\title{
The Use of a Lidar Forward-Looking Turbulence Sensor for Mixed- Compression Inlet Unstart Avoidance and Gross Weight Reduction on a High Speed Civil Transport
}

David Soreide

Boeing Defense and Space Group

Seattle, Washington

Rodney K. Bogue

L.J. Ehernberger

NASA Dryden Flight Research Center

Edwards, California

Jonathan Seidel

NASA Lewis Research Center

Cleveland, Ohio

July 1997

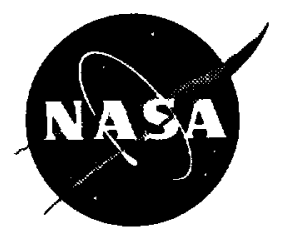

National Aeronautics and

Space Administration

Dryden Flight Research Center

Edwards, California 93523-0273 


\title{
THE USE OF A LIDAR FORWARD-LOOKING TURBULENCE SENSOR FOR MIXED-COMPRESSION INLET UNSTART AVOIDANCE AND GROSS WEIGHT REDUCTION ON A HIGH SPEED CIVIL TRANSPORT
}

\author{
David Soreide, ${ }^{*}$ Rodney Bogue, ${ }^{\dagger}$ Jonathan Seidel, ${ }^{\ddagger}$ L.J. Ehernberger ${ }^{\S}$
}

\begin{abstract}
$\underline{\text { Abstract }}$
Inlet unstart causes a disturbance akin to severe turbulence for a supersonic commercial airplane. Consequently, the current goal for the frequency of unstarts is a few times per fleet lifetime. For a mixed-compression inlet, there is a tradeoff between propulsion system efficiency and unstart margin. As the unstart margin decreases, propulsion system efficiency increases, but so does the unstart rate. This paper intends to first, quantify that tradeoff for the High Speed Civil Transport (HSCT) and second, to examine the benefits of using a sensor to detect turbulence ahead of the airplane. When the presence of turbulence is known with sufficient lead time to allow the propulsion system to adjust the unstart margin, then inlet unstarts can be minimized while overall efficiency is maximized. The NASA Airborne Coherent Lidar for Advanced In-Flight Measurements program is developing a lidar system to serve as a prototype of the forward-looking sensor. This paper reports on the progress of this development program and its application to the prevention of inlet unstart in a mixed-compression supersonic inlet. Quantified benefits include significantly reduced takeoff gross weight (TOGW), which could increase payload, reduce direct operating costs, or increase range for the HSCT.
\end{abstract}

\footnotetext{
"Principle Engineer, Boeing Defense \& Space, Seattle, Washington, AIAA Member.

${ }^{\dagger}$ Staff Scientist, NASA Dryden Flight Research Center, Edwards, California, 93523-0273, (805) 258-3193, AIAA Member.

${ }^{\ddagger}$ Aerospace Technologist, NASA Lewis Research Center, Cleveland, Ohio 44135-3191.

$\$$ Aerospace Engineer, NASA Dryden Flight Research Center, Edwards, California, 93523-0273, AIAA Associate Fellow.

Copyright (1) 1997 by the American Institute of Aeronautics and Astronautics, Inc. No copyright is asserted in the United States under Title 17 , U.S. Code. The U.S. Government has a royalty-free license to exercise all rights under the copyright claimed herein for Governmental purposes. All other rights are reserved by the copyright owner.
}

\section{$\underline{\text { Nomenclature }}$}

ACLAIM

Airborne Coherent Lidar for Advanced In-Flight Measurements

ECU environmental control unit

HSCT High Speed Civil Transport

lidar light distance and ranging

MSU mass storage unit

P/CEU power/control electronics unit

SFC specific fuel consumption

SPU signal processing unit

TOGW takeoff gross weight

XCVR transceiver

A

$A_{c}$

$A_{o}$

$k$

$k_{\text {cutoff }}$

$k_{\mathrm{o}}$

$L_{\mathrm{o}}$

M

$N_{\text {zero }}$

altitude, $k m$

capture area of the supersonic inlet

effective capture area ( $A_{c}$ minus the air not entering the inlet at the lip)

wave number, $/ \mathrm{m}$

inverse of the smallest turbulence size effective in causing unstarts

inverse of largest turbulence size

largest turbulence size

Mach number

rate at which a random variable $(V)$

crosses its nominal mean value

probability of encountering turbulence over a portion of a route or airframe life

$P(\sigma) \quad$ probability density of $\sigma$ (in a specified region) exposed to turbulence intensities 


$$
\begin{aligned}
& P_{\text {stratosphere }} \text { probability of encountering a given } \\
& \text { threshold turbulence value in the } \\
& \text { stratosphere } \\
& P_{I I} \quad \text { free stream total pressure } \\
& P_{12} \quad \text { total pressure downstream of the normal } \\
& r \\
& R \\
& R(V) \quad \text { rate at which the random variable } V \text { is } \\
& \text { exceeded } \\
& s \quad \text { standard deviation of the } \log \text { of } \sigma \\
& S_{i} \quad \text { one-sided Kolmogorov power spectral } \\
& \text { density }
\end{aligned}
$$

\subsection{Introduction}

Atmospheric turbulence can adversely affect the operation of supersonic aircraft propulsion systems by causing engine inlet unstart. Ride quality degradation as well as degradation in structural lifetime and integrity are additional problems that result from turbulence encounters. Advanced aircraft control system designs are expected to alleviate these problems by detecting atmospheric turbulence so that the undesirable effects on aircraft operations can be suppressed. This paper addresses the use of a pulsed lidar sensor that provides warning of impending turbulence encounters to avoid inlet unstarts in supersonic aircraft with mixedcompression inlets. Strategies for applying the sensor are addressed, the sensor system and operation are described, and the benefits of sensor use is quantified for the High Speed Civil Transport (HSCT) program. For the purposes of this paper, only unstarts that are caused by atmospheric turbulence are considered.

Although other mechanisms, such as maneuvers, can cause the inlet to unstart, atmospheric turbulence is the least controllable and therefore, the most important factor in avoiding operational problems. For a supersonic commercial airplane, inlet unstart is a phenomenon that causes a disturbance akin to a moderate to heavy turbulence encounter. Consequently, the current goal for the frequency of unstarts is in the range of a few times per fleet lifetime. The required unstart rate for commercial service is still a subject of discussion and is addressed in some detail in the body of this paper.

\subsection{Supersonic Mixed-Compression Propulsion System} Inlet

Supersonic propulsion systems require a specially designed and controlled inlet to supply high-pressure subsonic air to the compressor face of the turbine engine. Efficient operation at supersonic conditions anticipated for the HSCT (Mach 2.4) requires the use of a mixed-compression inlet that uses a series of shock waves to both compress and reduce the Mach number of the incoming engine air supply. Existing mixedcompression inlets utilize complex control mechanisms that change the configuration of the inlet in response to the needs of the turbine engine under varying acceleration, climb, and cruise conditions.

As shown in the upper part of figure 1 , in the started condition the inlet control system maintains the shock pattern during supersonic operation. As the oncoming air enters the inlet, the spike tip creates the initial oblique shock wave, that for cruise conditions (and optimum inlet efficiency) approaches contact with the cowl lip. As the air proceeds further into the inlet, it enters the supersonic diffuser section where a series of weak oblique shock waves are used to increase the static pressure and to decrease the Mach number of the engine air supply. Downstream of the inlet throat, the Mach number of the inlet becomes subsonic through a weak normal shock wave and enters into the subsonic diffuser for further Mach number reduction and pressure recovery. Instability of the shock pattern in extreme situations can cause the pattern to be disrupted, and the 


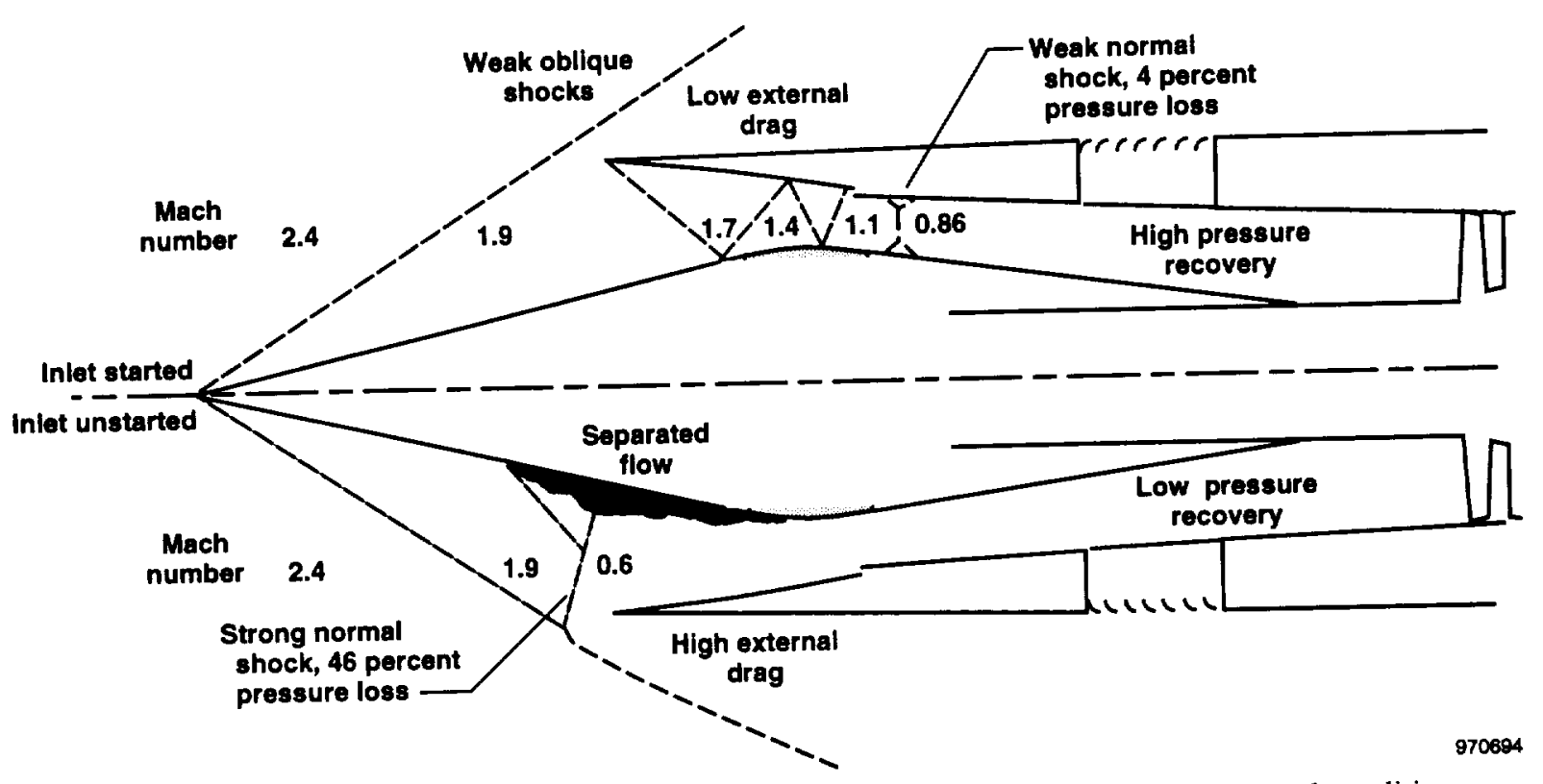

Figure 1. A generic mixed-compression supersonic engine inlet showing started and unstarted conditions.

weak normal shock in the inlet throat area nearly instantaneously travels forward until it stands off the inlet entrance causing an inlet unstart. Figure 1 shows this inlet unstart condition.

The inlet unstart process precipitates a rapid increase in inlet drag. The air supply to the engine is disrupted and a secondary effect of the inlet unstart may be an engine stall, causing the engine thrust to be drastically reduced. Flight crew members who have experienced supersonic inlet unstarts in the SR-71 aircraft, Dryden Flight Research Center, Edwards, California, have described the startling effect of the phenomenon. Automatic controls are used to maintain control of the aircraft and initiate the re-start procedure.

The tradeoff in inlet operation is between efficiency and stability. Increased efficiency is achieved (and decreased stability) with the normal shock wave closer to the throat; increased stability is achieved (and decreased efficiency) with a location farther downstream from the throat. A control system that varies the geometry of the centerbody (or translates the centerbody position) maintains the shock in a stable configuration in response to the combined demands of the engine and flight conditions. It is common to accept reduced efficiency in a mixed-compression inlet by moving the shock wave farther downstream from the optimal throat position in order to increase inlet stability and increase the unstart margin (resistance to natural disturbances that would precipitate an unstart). Bypass doors are used downstream in the subsonic diffuser section to match inlet air capture to engine demand and to provide fast response shock position control. Between 0.1 and $1.0 \mathrm{sec}$ of advance warning must be provided to permit the inlet to reset at a more conservative operating margin in time to prevent a potential unstart precipitated by the atmospheric turbulence.

\subsection{Effects of Unstart Margin Adjustment}

If the presence of turbulence is known with sufficient lead time to allow the propulsion system to adjust the unstart margin, then the propulsion system can operate at a high-efficiency and low-unstart margin for the maximal amount of time. This, in turn, leads to improved average propulsion system efficiency. This paper presents calculations detailing this tradeoff and quantifying the unstart margin required during HSCT operation.

To achieve both high efficiency and safe operation requires a sensor that can remotely detect the turbulence. A lidar-based sensor is a leading candidate to acquire this remote information and the final portion of this paper describes an ongoing program to develop a lidar for this purpose. This system will be tested at NASA Ames Research Center, Moffet Field, California, on the DC- 8 laboratory to validate the basic lidar performance in a subsonic environment. Tests on the SR-71 aircraft are being proposed which would allow the lidar-measurement of turbulence along the flightpath to directly assess the impact on the supersonic inlet. Because the SR-71 flight envelope encompasses the 
HSCT cruise speeds and altitudes at which meteorological structures differ from subsonic transport aircraft, these data would be invaluable in evaluating the benefit and feasibility of a lidar system for the HSCT. The benefits of a lidar system for this purpose are great. Models for HSCT aircraft at the NASA Lewis Research Center, Cleveland, Ohio, show as much as 8-percent takeoff gross weight (TOGW) reduction for the translating centerbody inlet. The TOGW reduction could benefit the HSCT by providing, for example; increased payload, reduced direct operating cost, or increased range. As a consequence, evaluation of the lidar technology for the HSCT should be given a high priority.

\subsection{Calculation of Unstart Rate and Unstart Margin in Turbulence}

The unstart margin will be parameterized by a variation in free-stream Mach number sufficient to unstart the inlet. The unstart rate is then the rate at which atmospheric turbulence causes the Mach number to exceed this unstart margin. This rate can also be referred to as the exceedance rate. The method for calculating the unstart rate in turbulence is described in appendix $A$. The mathematics of exceedance were developed by Rice ${ }^{1}$ and the application of these mathematics to supersonic inlets was described by Barry. ${ }^{2}$ Figure 2 shows the tradeoff between the unstart rate and the unstart margin expressed as a perturbation in free-stream axial Mach number. Two turbulence intensities are shown that are characteristic of light and heavy turbulence intensity within a turbulent patch $\left(\varepsilon=2 \times 10^{-5}\right.$ and $\left.\varepsilon=8 \times 10^{-5}\right)$ where $\varepsilon$ is the eddy dissipation rate proportional to turbulence intensity to the third power.
Because the relation between the unstart rate and the unstart margin is exponential, the slope of the curves in figure 2 is remarkably steep. Changing the unstart margin by Mach 0.01 changes the unstart rate by nearly an order of magnitude over the majority of the plotted region. This relationship allows a dramatic improvement in propulsion system efficiency (appendix B).

\subsection{Conversion of Turbulence Components to Equivalent Mach Number Perturbations}

Atmospheric turbulence includes four components, the three axes of velocity turbulence and temperature. Because temperature and all three components of velocity affect the inlet by changing the throat Mach number, we can combine them into a single Mach number disturbance at the inlet lip. The net disturbance variance is the sum of the individual variances, because the components are uncorrelated. The variation of the axial component is the Mach number variation. Because Mach number is given by $M \propto \frac{V}{\sqrt{T}}$ then variations in Mach number caused by temperature changes can be approximated using the differential Taylor series approach. Note that $\Delta M \propto M \frac{\Delta T}{2 T}$, where $V$ is the true airspeed, $T$ is ambient temperature, and $M$ is average Mach number. The two transverse components of turbulence can be converted to a combined angle at the inlet lip.

According to D.M. Sommerfield of Boeing Commercial Airplane Company, Seattle, Washington, to

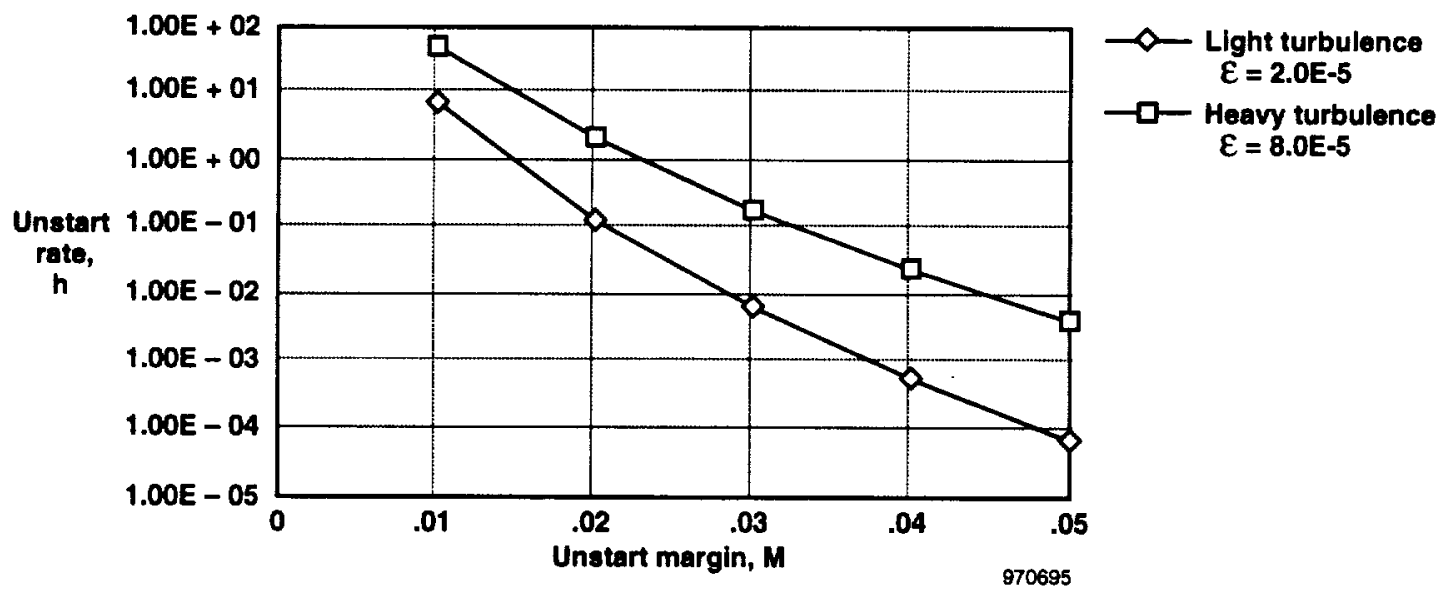

Figure 2. Unstart rate as a function of unstart margin for two turbulence intensities. 
make the conversion from angle of incidence at the inlet lip to unstart margin, wind tunnel data relating Mach number required to unstart the inlet, to angle of incidence at the inlet is used. These data were obtained in the NASA Lewis Research Center's $10 \times 10-\mathrm{ft}$ Supersonic Wind Tunnel. The data itself is Boeing proprietary, but has been used here to establish the relationship between the angle of incidence (also called the alpha tolerance) and the unstart margin. Only this result is presented here. The relation between these two variables is non-linear, but this slope can be approximated by connecting the end points. This approach produces a value that is conservative and in the range of 0.02 to $0.035 \mathrm{M} / \mathrm{deg}$. Here the conservative $0.035 \mathrm{M} / \mathrm{deg}$ is used.

All four turbulence components are locally isotropic and described by a common power spectral density, the Kolmogorov spectrum. The mathematics for this process are shown in appendix $\mathbf{A}$.

\subsection{Strategies for Setting the Unstart Margin}

If the unstart margin is increased then the unstart rate is reduced. Unfortunately, when the unstart margin is increased, the pressure recovery ratio of the supersonic inlet goes down, decreasing the propulsion system efficiency as discussed in section 1.1. For this reason, the ideal would be to set the unstart margin at a level that just meets the unstart rate criterion. Setting it higher than that will reduce the efficiency, which will in turn increase the TOGW. To quantify the benefits of a forward-looking turbulence sensor, the turbulence environment must be specified and the target unstart rate defined. The unstart rate criterion is the subject of discussion within the HSCT community, but the value of $10^{-6} / \mathrm{h}$ is considered reasonable and is used in this paper.

Given this value $\left(10^{-6} / \mathrm{h}\right)$, two strategies for setting the unstart margin and comparing their impact on the HSCT are investigated. The first is to fix the unstart margin so that the average unstart rate is $10^{-6} / \mathrm{h}$ over a given flight route. The second strategy is to vary the unstart margin to match the turbulence level in which the airplane finds itself. This strategy is based on the fact that atmospheric turbulence is found in patches, well-defined regions of high turbulence that are embedded in a generally low-turbulence environment. The method of varying the unstart margin to maintain a fixed unstart rate has a significant advantage over the method of fixed unstart margin. This method will be demonstrated in section 2.2.1.2, and a heuristic explanation is included in appendix $B$.
This second strategy, varying the unstart margin, requires that a sensor be available to assess the turbulence far enough ahead of the airplane to ensure that the unstart margin can be changed before the turbulence is encountered. This distance is estimated to range from 100 to $1000 \mathrm{~m}$, corresponding to 0.1 to $1 \mathrm{sec}$ at Mach 2.4. Although other sensors are being considered, the most appropriate sensor seems to be a lidar one Such a sensor system is being developed under the Airborne Coherent Lidar for Advanced In-Flight Measurements (ACLAIM) program, and will be discussed in more detail in section 3 of this paper.

\subsubsection{Calculation of Unstart Margin for Fixed Margin and Fixed Unstart Rate}

The strategy of section 2.1 converts atmospheric turbulence intensity expressed in terms of the eddy dissipation rate to Mach number fluctuations. Section 2.2 focuses on the mathematical formalism connecting the Mach number fluctuations to exceedance rate (appendix A). A comparison of the two strategies is provided next.

2.2.1.1 Fixed Unstart Margin. The problem of calculating the unstart rate with a fixed unstart margin is addressed first. This begins with construction of a table of the eddy dissipation rate and the prior probability of turbulence as a function of distance. The process is complicated by the fact that the eddy dissipation rate and the prior probability of turbulence vary with altitude.

Once the routes were laid out on the maps given in Atmospheric Disturbance Environment Definition, ${ }^{3}$ the distance in each eddy dissipation rate interval was measured and recorded. The term interval, as used in this context, represents a distance along the selected HSCT route during which the eddy dissipation rate $(\varepsilon)$ and the prior probability of turbulence $(P)$ are assumed to be a constant value. The flight distance was measured only over the ocean. The measurement was done this way to approximate the distance at supersonic cruise rather than the total flight distance. A generic mission profile was used to estimate the altitude along the flight track.

A table was constructed using the previouslyreferenced intervals. An example table is shown in appendix $C$. For the eddy dissipation rate and prior probability, the intervals are the distance between the points where the flightpath crosses the boundary from one eddy dissipation rate to a different rate on the maps in the Atmospheric Disturbance Environment 
Definition, ${ }^{3}$ The value of each parameter is set halfway between the two rates.

The effect of altitude on the eddy dissipation rate $(\varepsilon)$ and the prior probability of turbulence $(P)$ is approximated by a multiplier, which is defined in equations 1 and 2 . For example, at an altitude of $10 \mathrm{~km}$ the eddy dissipation rate is four times larger than the stratospheric $(20 \mathrm{~km})$ value given in the Atmospheric Disturbance Environment Definition ${ }^{3}$ and the prior probability is 6.2 times larger.

$$
\begin{gathered}
\varepsilon=\left(\frac{20}{A}\right)^{2} \varepsilon_{\text {stratosphere }} \\
P=\left(1.73\left(\frac{20}{A}\right)^{2}-.72\right) P_{\text {stratosphere }}
\end{gathered}
$$

where $A$ is the altitude in kilometers, $\varepsilon_{\text {stratosphere }}$ is the eddy dissipation rate in the stratosphere, and $P_{\text {stratosphere }}$ is the probability of encountering turbulence in the stratosphere. Both of these quantities are derived in reference 3 . From this reference, one can extract the eddy dissipation rate and prior probability for each interval, calculate the unstart rate for those parameters using the derivation in appendix $\mathrm{A}$, and then do a weighted average of the unstart rate over the route profile.

The installation of the inlet in a real airframe will inevitably cause flow distortions. Based on estimates of these effects, a margin of $0.03 \mathrm{M}$ has been added to all the unstart margins calculated. Using the above procedure, the fixed unstart margin, to maintain an average unstart rate of $10^{-6} / \mathrm{h}$ over a flight from San Francisco to Tokyo can be calculated. This route has been chosen because it is relatively turbulent. The fixed unstart margin for this route including the installation effects is $0.084 M$.

2.2.1.2 Fixed Unstart Rate. If a turbulence sensor is used to determine whether the airplane is approaching a turbulent patch, then the unstart margin can be reduced in-between the turbulent patches. In those quiet regions, the eddy dissipation rate will be on the order of $10^{-6} \mathrm{~m}^{2} / \mathrm{sec}^{3}$. Because of the turbulence alone, this level of turbulence will allow us to set the unstart margin, to $0.02 \mathrm{M}$ or less. For calculation, set the unstart margin between the turbulent patches (a combination of the installation and turbulence effects) to a constant $0.05 \mathrm{M}$. Then the average unstart margin can be calculated where the unstart margin is set by the turbulence level for the fraction of the time the airplane is expected to be in turbulence and is $0.05 \mathrm{M}$ for all other regions.
Using the table of eddy dissipation rate (discussed in section 2.2.1.1), and prior probability of turbulence calculated earlier (but now varying the unstart margin to maintain a fixed unstart rate of $10^{-6} / \mathrm{h}$ ), the average unstart margin for the San Francisco to Tokyo route is $0.052 M$. This is significantly lower than $0.084 M$ calculated for a fixed unstart margin. In order to assess the effect of this difference, consider the effect of the unstart margin on the propulsion system.

\subsubsection{Supersonic Inlet Efficiency and the Impact on} the HSCT. In order to model the benefits of reducing the unstart margin a specific inlet configuration must be chosen. One inlet configuration being considered for the HSCT is a translating centerbody inlet whose general configuration is the same as that used on the SR-71 aircraft. The impact on the HSCT assumes the use of a translating centerbody inlet configuration. The efficiency of the inlet is parameterized by the pressure recovery ratio, the ratio of the total pressure at the inlet lip to the actual total pressure at the entrance to the engine itself. The pressure recovery ratio of this inlet is a complex function of the throat Mach number, centerbody position, and inlet mass flow; therefore is a strong function of unstart margin. The unstart margin is set by moving the centerbody. Mass flow can vary at a given centerbody position, and the propulsion system efficiency calculation is performed at the optimum mass flow condition. In addition, a quick response bypass control mechanism is used to increase inlet mass flow, stabilizing the terminal shock. In this study, only alpha tolerance (angle of incidence) at the cruise Mach number $(M=2.4)$ was analyzed. This was done because the aircraft will spend very little time at supersonic Mach numbers below 2.4, and the unstart rate for Mach numbers lower than 2.4 is significantly lower. Figure 3 shows the propulsion system impacts of unstart alpha tolerance at the cruise Mach number.

As tolerance requirements are increased, installed thrust and specific fuel consumption (SFC) are penalized because of the reduced mass flow and total pressure recovery. Using the degradation in SFC as the unstart margin is increased, the impact of increasing the unstart margin in terms of the TOGW of the HSCT airplane can be calculated. This calculation is based on generic models of the airplane configuration and performance (fig. 4).

\subsubsection{Quantified Benefits for the HSCT Operation}

In order to calculate the effect of unstart margin on the propulsion system efficiency, the Mach number unstart margins need to be converted to alpha tolerances (sections 2.2.1.1 and 2.2.1.2). The conversion factor is 


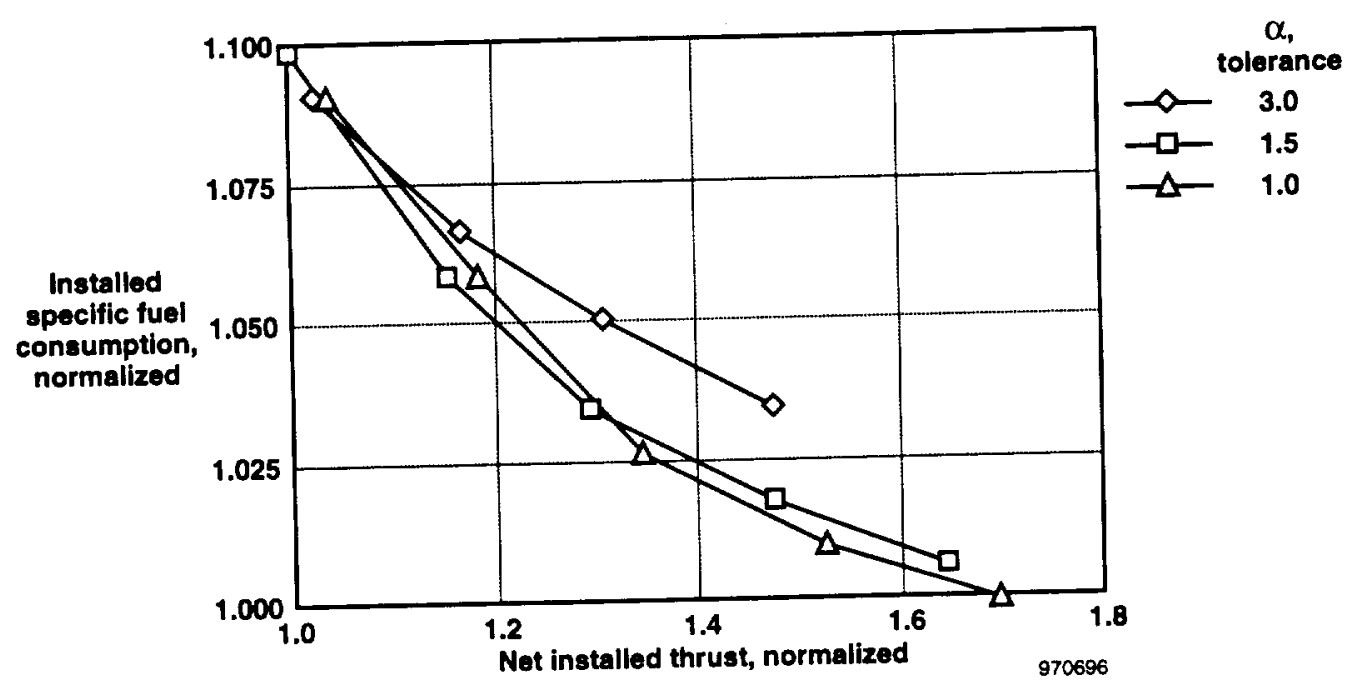

Figure 3. Impact of inlet operating point on engine performance.

approximately $0.035 \mathrm{M} / \mathrm{deg}$, (section 2.1 ). Converting to effective angles, calculations using figure 4 show that the unstart margin without a forward-looking sensor $(0.084 M)$ is $2.4^{\circ}$, and with a forward-looking sensor $(0.052)$ is $1.5^{\circ}$. Reading from figure 4 , without the forward-looking sensor, the TOGW would increase by approximately 8 percent. The advantage of a forward-looking sensor is substantial, and a lidar system could serve as this forward-looking sensor.

\subsection{Lidar Forward-Looking Turbulence Sensor}

\subsection{Lidar Background}

The operation of the coherent light detection and ranging (lidar) sensor relies on backscatter from aerosol particles in the atmosphere to obtain information about atmospheric motion. These particles are fully entrained in the atmosphere, so knowledge of the particle motion also gives information on air motion. ${ }^{4} \mathrm{~A}$ typical lidar system includes a pulsed laser coupled with a telescope and detector apparatus to direct the light into atmospheric areas of interest and to collect and detect the backscattered energy. Because only a small fraction of the transmitted laser energy is returned as a backscattered signal, it is necessary to transmit high-energy pulses. The lidar concept is similar to radar except that light radiation is used in place of radio frequency energy. In addition, the target is a diffuse collection of aerosols instead of water droplets or hard objects, such as aircraft. In operation, the laser transmits a 500 nanosecond pulse (longer or shorter depending upon the desired range and Doppler resolution).

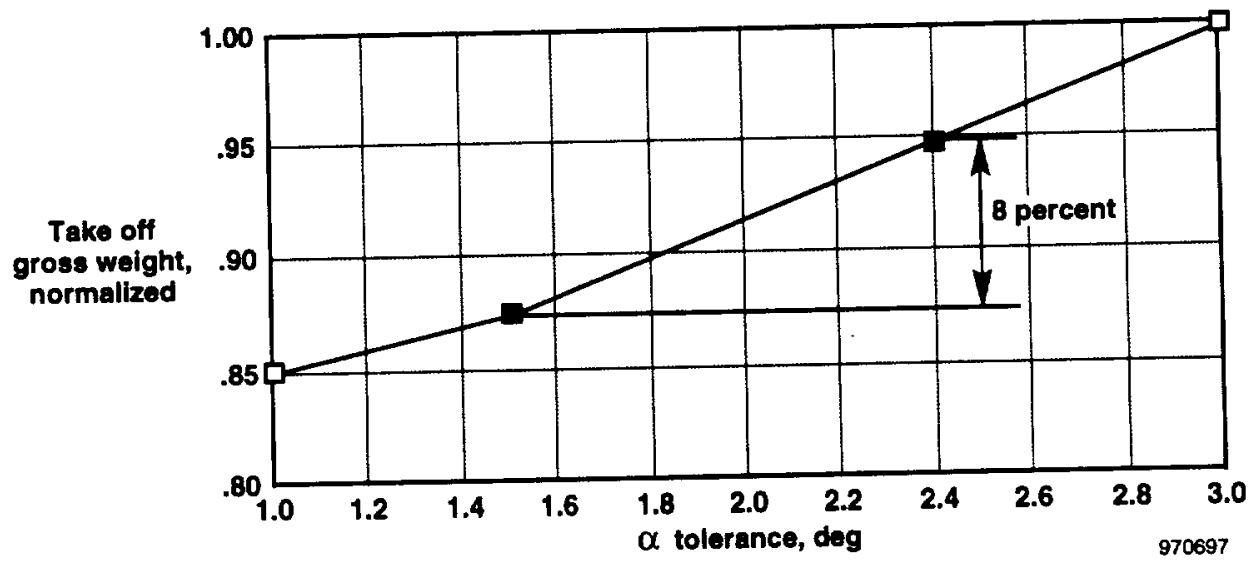

Figure 4. Impact of increased unstart margin on aircraft gross weight. 
This laser pulse energy impinges on aerosols, and a small percentage is scattered back to the transmitter where it is collected and coherently detected. The relative motion between the aerosols in the area of interest (determined by azimuth, elevation, and range selection) and the lidar sensor causes a shift in the frequency of the returned signal called the Doppler shift. Time gating of the detection process is used to discriminate the range from which the backscattered signal is being received. By knowing the wavelength of the transmitted pulse and the magnitude and spectral width of the Doppler shift in the return signal, the relative motion between the aircraft and the aerosols in the area of interest may be determined, and thereby the atmospheric motion of interest (mean velocity and turbulence).

The sources of atmospheric particles include volcanic injection, salt spray evaporation, and dust storms. ${ }^{5}$ The particles play a role in many atmospheric processes. The net effect of natural particle formation and subsequent participation in natural processes is that the size distribution and number density vary over several orders of magnitude under normal conditions. The dominant source of aerosols in the stratosphere is volcanic eruptions. Sulfuric acid droplets constitute the primary population. The troposphere is populated with the aerosol "fallout" from the stratosphere as well as from surface sources, such as salt spray evaporation; dust storms; and urban, industrial, or agricultural pollution.

For satisfactory lidar operation, understanding the variation in aerosol optical backscatter values to assure that the sensor will perform satisfactorily under all conditions is critical. The stratospheric aerosol population maintains a slowly declining density characteristic that is stable over timeframes of several years with rapid density increases occurring during periods of volcanic activity. The slow decline of the stratospheric population results from slow but steady and widespread aerosol sedimentation into the troposphere, combined with rapid but episodic transport into the troposphere during localized tropopause fold events. Weather activity substantially influences and is influenced by the aerosol population in the troposphere. Particles act as nucleation centers to allow water droplets to develop and, thereby, form clouds or rain or both. In turn, droplet formation massively depopulates the atmosphere of aerosols and creates very clean atmospheric conditions. Weather activity can occur over timeframes of a few minutes to hours; thus, the aerosol concentrations in the troposphere exhibit wide short-term variations. The middle and upper troposphere and lower stratosphere present the most challenging conditions for lidar operation, because the lowest aerosol populations are to be found in these regions. In spite of these low aerosol density conditions, there is evidence of a tropospheric aerosol backscatter background mode, which is stable over seasonal, diurnal, geographical, and weather variations. ${ }^{6}$ In essence, the lowest values of aerosol backscatter at the 2 micron $(\mu \mathrm{m})$ wavelength are expected to occur near an altitude of 9 or $10 \mathrm{~km}$. Even though the predicted backscatter levels are higher in the region of the stratospheric HSCT cruise altitude, a lidar sensor must be able to operate under supersonic climb and descent conditions in the middle and upper troposphere where inlet unstarts must also be avoided.

\subsection{Airborne Coherent Lidar for Advanced In-Flight Measurements Development Program}

The NASA ACLAIM program has as a primary objective, the remote measurement of turbulence at a range of $1 \mathrm{~km}$ under conditions with an optical atmospheric backscatter coefficient $(\beta)$ as low as $5 \times 10^{-11} / \mathrm{m} /$ steradian. These measurements are being accomplished using laser technology at an eye-tolerant wavelength of $2.022 \mu \mathrm{m}$. If this objective can be attained, existing lidar measurements and theoretical predictions would suggest that turbulence measurements from sea level to close to an altitude of $85 \mathrm{kft}$ should be possible.

The ACLAIM program is developing and flight testing a sensor on NASA research aircraft, including the SR-71 aircraft. This program is also investigating the atmospheric environment to establish the feasibility of a lidar sensor. This development and testing combines the use of laser and optical technology and advanced flight test techniques in an aircraft flight environment. Because the program relies on an atmosphere with a sufficient population of aerosol material to provide backscatter targets for the sensor, atmospheric science is a key discipline to providing estimates for the tropospheric and stratospheric aerosol environment.

A cooperative effort between government agencies, private industry, and academia is being used to accomplish the ACLAIM activity. Coherent Technologies, Inc., Lafayette, Colorado, is building the lidar-based sensor system. The Boeing Company, Seattle, Washington, is providing HSCT technical requirements. Modeling of the HSCT propulsion system is being accomplished under the Critical Propulsion Components program at the NASA Lewis. The University of Alabama at Huntsville, Alabama, and NASA LaRC are providing atmospheric science support. NASA Dryden is leading the effort and providing overall program management. This team is augmented by a 
technical steering committee comprised of NASA and the Department of Defense representatives.

\subsection{Lidar System}

A key element in the ACLAIM program is the development of the lidar-based sensor to be used as the primary atmospheric sensing device. The project is developing and evaluating in flight tests, a high-pulse energy and high-pulse repetition frequency lidar system. These flight experiments are evaluating the ability of lidar techniques to remotely measure turbulence over flight envelopes representative of subsonic and supersonic transport aircraft. The sensor is based on advanced high-pulse energy ( -20 millijoule) and diode-pumped $2 \mu \mathrm{m}$ laser technology originally used for wind sensing.

The lidar system is a self-contained, modular configuration composed of five modules: Transceiver (XCVR), Power/Control Electronics Unit (P/CEU), Signal Processing Unit (SPU), Mass Storage Unit (MSU), and Environmental Control Unit (ECU). Figure 5 illustrates these modules being located in the nose bay of the SR-71 aircraft.

The transceiver performance specifications were derived for the SR-71 flight experiment based upon previous transceiver experience, laboratory risk reduction efforts (including demonstrations currently being performed), and flight experiment objectives. Table 1 lists these specifications.
Table 1. Transceiver specifications.

\begin{tabular}{cc}
\hline Parameter & Value \\
\hline Wavelength, $\mu m$ & 2.022 \\
Laser pulse energy, $m J$ & -20 \\
Laser pulse duration, $\mathrm{nsec}$ & 450 \\
Pulse repetition frequency, $\mathrm{Hz}$ & 100 \\
${\text { Size, } \mathrm{ft}^{3}}^{3}$ & 11 \\
Weight, $\mathrm{lb}^{\mathrm{P}}$ & 400 \\
Power, $\mathrm{kW}$ & 3.6 \\
\hline \hline
\end{tabular}

\subsection{Flight Experiments}

A set of flight experiments will be performed using the lidar system. These results will be used to assess the usefulness of these techniques for avoiding inlet unstart for supersonic aircraft and for improving ride quality for supersonic and subsonic aircraft. Flight experiments are planned sequentially for the NASA DC-8 and SR-71 research aircraft. Each platform provides a contribution to the characterization of the lidar, while incrementally reducing technical risk to the program.

The DC-8 Airborne Laboratory at NASA Ames Research Center, is a re-engined aircraft with an altitude ceiling of $41,000 \mathrm{ft}$. This laboratory has extensive provisions for supporting flight experiments in a pressurized room-temperature environment conducive to hands-on experiment adjustment and optimization. The DC-8 laboratory serves as a cost efficient means for

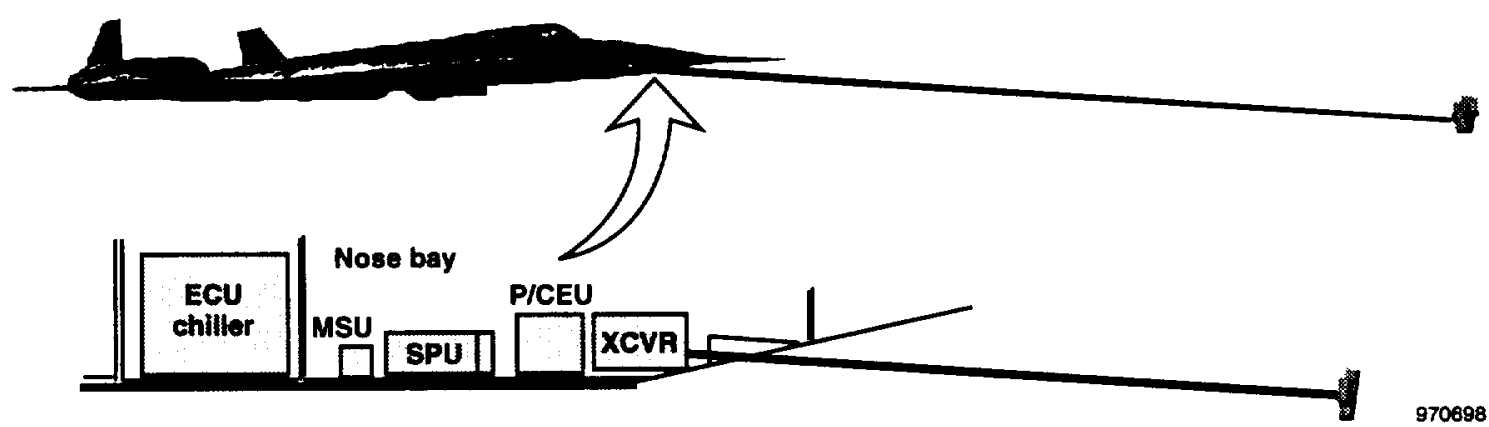

Figure 5. The lidar system modules and mounting location in SR-71 aircraft. 
system shakedown, provides verification of system function and performance, and allows laser engineers the opportunity for system optimization and calibration. The DC-8 laboratory is also amenable to flexible flight plans so as to maximize the efficiency in gathering relevant turbulence data.

The SR-71 aircraft at NASA Dryden can operate at Mach 3.2 cruise condition and can reach altitudes approaching 90,000 ft. To match the anticipated HSCT flight envelope, these flight experiments will operate the aircraft at Mach 2.4 and an altitude of $65,000 \mathrm{ft}$. The SR-71 fights will establish system operating parameters that define a limiting boundary for successful turbulence characterization. These parameters include atmospheric backscatter coefficient, airspeed or Mach number, pulse energy, measurement range, and system optical configuration.

\subsection{Concluding Remarks}

The benefits of using a forward-looking sensor to detect turbulence and adjust the unstart margins based on these measurements, have been shown to be significant for the High Speed Civil Transport (HSCT). With this turbulence detection and variable inlet margin approach, the calculations presented here indicate that the HSCT takeoff gross weight (TOGW) could decrease by as much as 8 percent based on a translating centerbody inlet. This TOGW reduction can be used to increase the payload, to increase range, or to decrease the direct operating costs. A lidar system is being developed under the NASA Airborne Coherent Lidar for Advanced In-Flight Measurements (ACLAIM) program which could be used to prototype such an unstart protection system. A test program using a DC- 8 testbed aircraft will explore the lidar capabilities in subsonic flight for regions of the atmosphere that challenge the lidar operation because of low particulate backscatter conditions. Following the DC-8 tests, a test phase using the SR-71 aircraft will explore the effectiveness of the lidar capabilities for measuring turbulence in supersonic flight under conditions similar to those expected to be encountered by the HSCT in commercial service. The experience gained in developing the lidar system and the subsequent prototypes will substantially reduce the risks involved in applying this technology to a supersonic commercial airplane. 


\section{Appendix A}

Equation (A1) is Rice's equation formulated to express the rate $R(\Delta M)$, at which a parameter (for example change in Mach number) passes through a threshold value, $\Delta M$, with a positive slope ( $\Delta M$ would be the unstart margin).

$$
R(\Delta M)=N_{z e r o} \int_{0}^{\infty} e^{-\frac{\Delta M^{2}}{2 \cdot r \cdot(\sigma)^{2}}} P(\sigma) d \sigma
$$

where $\sigma^{2}$ is the variance of the parameter (Mach number) and $r$ is given by

$$
r=\frac{\int_{k_{0}}^{\infty} T(k)^{2} S(k) d k}{\int_{k_{0}}^{\infty} S(k) d k}
$$

where $S(k)$ is the atmospheric turbulent spectrum, $k$ is the wave number in cycles $/ \mathrm{m}, k_{o}=1 / L_{o}$ where $L_{o}$ is the largest turbulence size (the outer scale), and $T(k)$ is the linear transfer function of the supersonic inlet. $P(\sigma)$ is the probability density function of $\sigma$ (in the free atmosphere), and $N_{z e r o}$ is the rate at which the parameter crosses zero given by

$$
N_{z e r o}=\sqrt{\frac{\int_{k_{o}}^{k_{\text {curoff }}} k^{2} T(k)^{2} S(k) d k}{\int_{k_{o}}^{k_{\text {curoff }}} T(k)^{2} S(k) d k} \frac{1}{\pi}}
$$

where $k_{\text {cutoff }}$, the upper limit of integration, is set by the smallest scales of turbulence which are effective in causing unstarts. Multiplying equation (A1) by the prior probability of encountering turbulence gives the joint exceedance rate $R(\Delta M)$

$$
R(\Delta M)=P \cdot N_{z e r o} \int_{0}^{\infty} e^{-\frac{\Delta M^{2}}{2 \cdot r \cdot(\sigma)^{2}}} P(\sigma) d \sigma
$$

where $P$ is the prior probability of turbulence.

For atmospheric turbulence all four components of turbulence (the three Cartesian velocity coordinates and the temperature) are locally isotropic and described by a common power spectral density, the Kolmogorov spectrum, shown in equation (A5).

$$
S_{i}(k)=\alpha_{i} \varepsilon^{\frac{2}{3}} k^{-\frac{5}{3}}
$$

where $S_{i}(k)$ is the one-sided power spectral density, $\alpha_{i}=0.15$ for axial turbulence, $\alpha_{i}=0.2$ for transverse turbulence, $\alpha_{i}=0.39$ for temperature turbulence, and $\varepsilon$ is the eddy dissipation rate. Because their spectra are the same, the four disturbances can be combined to give an effective change in Mach number (section 2.1). For practical transfer functions $T(k), r \sigma^{2}$ as used in equation (A1), and $N_{\text {zero }}$ given in equation (A3), are only a function of $\varepsilon$, and the set of $\alpha_{i}$. The probability density function of $\sigma$ (and $\varepsilon$ ) is log-normal. This distribution is described in detail in reference 4 and is shown in equation (A4).

$$
P(\sigma)=\frac{1}{\ln (10) s \sigma \sqrt{2 \pi}} e^{\left(-\frac{2 \log \left(\frac{\sigma}{\sigma_{a}}\right)^{2}}{2 s^{2}}\right)}
$$

where $s$ is the standard deviation of the common logarithm of the disturbance intensity, and $\sigma_{a}$ is the geometric average of $\sigma$. Because $\sigma$ is proportional to $\varepsilon^{1 / 3}$, the probability density could be expressed as a function of $\varepsilon$. However, the form above is more convenient mathematically. Using the maps of $\varepsilon$ that are contained in reference 1 and equations (A1)-(A6), permits calculation of the rate at which the turbulent velocity exceeds a threshold, $\Delta M$. This rate is conditioned on the presence of turbulence, which is also mapped in reference 3 . A weighted integral of $R(\Delta M)$ over a given flight track gives the probability of an exceedance (or unstart) for that flight. 


\section{Appendix B}

The average unstart margin is reduced if it is varied to meet the requirements of the varying turbulence. This advantage arises from the fact that the unstart rate is related to the unstart margin by an exponential (equation 1). To illustrate this, let us consider a simple case, in which there are two turbulence intensities: one for smooth air and very negligible turbulence and the other for heavy turbulence characteristic of turbulence patches. These levels differ by a factor of between 1 and 50 , with the smaller turbulence level occurring 90 percent of the time, and the larger turbulence level being present 10 percent of the time. These ratios are in the range of the corresponding atmospheric variables. Now compare the unstart margin required for an average unstart rate of $10^{-6} \mathrm{~h}$ (fixed margin), with the average unstart margin that always maintains a rate of $10^{-6} / \mathrm{h}$ (fixed unstart rate) in figure B1.

In this simplified case, there are only two values of the unstart rate, and two values of the unstart margin. If the unstart margin is held fixed, then the average rate is dominated by high values which are many orders of magnitude larger than the unstart rate between the turbulent patches. Thus, the margin is also set to minimize what would otherwise be high unstart rate values. In the case of fixed unstart rates, the margin varies, and the average is affected relatively little by the peak margin values because these values are higher by less than a factor of three than the low values.

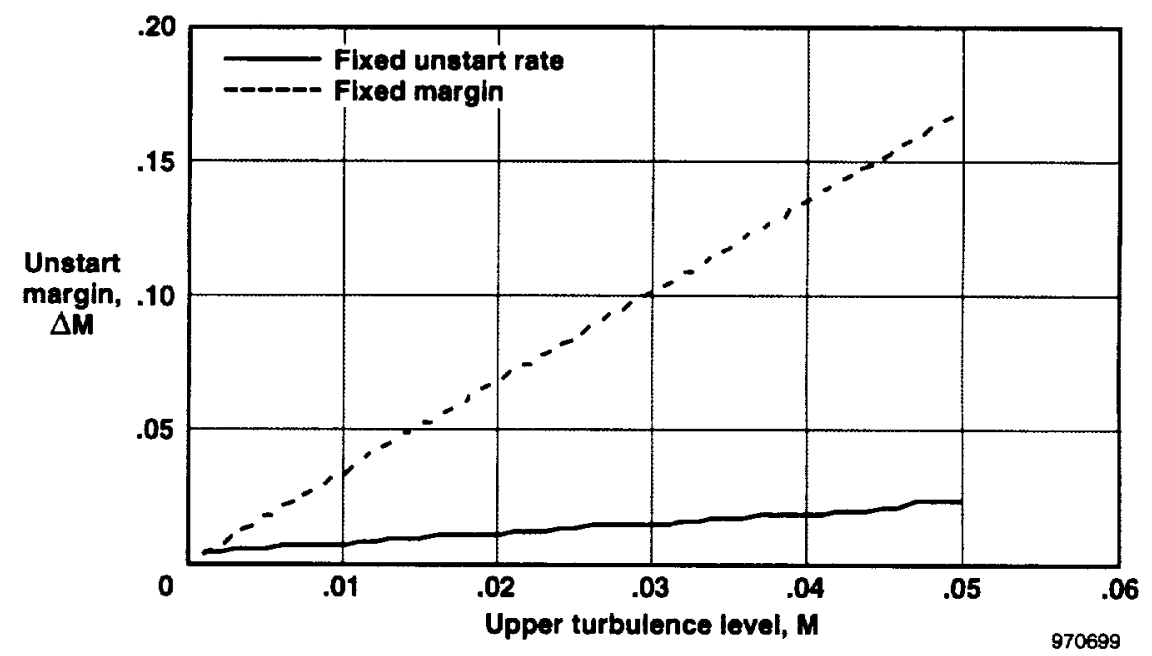

Figure B1. Distance, epsilon and prior probability of turbulence for the San Francisco to Tokyo route. 


\section{Appendix C}

Example table showing calculation of unstart margin for HSCT route intervals.

Table C1. Distance, epsilon, and prior probability of turbulence for the San Francisco to Tokyo route.

\begin{tabular}{|c|c|c|c|}
\hline Interval & $\begin{array}{c}\text { SF-Tokyo } \\
\text { (over water) } \\
\text { distance, nmi }\end{array}$ & $\begin{array}{l}\text { epsilon, } \\
10^{-5} \mathrm{~m}^{2} / \mathrm{s}^{3}\end{array}$ & $\begin{array}{c}\text { Prior } \\
\text { probability } \\
\% \\
\end{array}$ \\
\hline 1 & 37.11 & 4.05 & 5.89 \\
\hline 2 & 37.31 & 3.62 & 5.15 \\
\hline 3 & 36.91 & 3.27 & 4.55 \\
\hline 4 & 51.10 & 2.87 & 3.86 \\
\hline 5 & 51.16 & 2.65 & 3.48 \\
\hline 6 & 78.56 & 2.46 & 3.15 \\
\hline 7 & 148.02 & 2.30 & 2.88 \\
\hline 8 & 561.80 & 2.22 & 2.74 \\
\hline 9 & 705.09 & 2.12 & 2.56 \\
\hline 10 & 37.11 & 3.53 & 2.57 \\
\hline 11 & 742.20 & 3.37 & 2.39 \\
\hline 12 & 667.98 & 2.98 & 1.99 \\
\hline 13 & 74.22 & 2.98 & 3.32 \\
\hline 14 & 148.44 & 5.36 & 3.32 \\
\hline 15 & 44.16 & 7.76 & 3.33 \\
\hline 16 & 30.06 & 8.32 & 3.71 \\
\hline 17 & 37.11 & 11.99 & 4.27 \\
\hline 18 & 37.11 & 13.12 & 4.84 \\
\hline 19 & 37.11 & 14.14 & 5.36 \\
\hline Total distance & $3,563.00$ & & \\
\hline
\end{tabular}




\section{$\underline{\text { References }}$}

${ }^{1}$ Rice, S.O., "Mathematical Analysis of Random Noise," Bell System Technical Journal, July 1944, p. 282.

${ }^{2}$ Barry, F.W., Development of Atmospheric Gust Criteria for Supersonic Inlet Design, NASA CR-114372, Dec. 1968.

${ }^{3}$ Tank, W.G., Atmospheric Disturbance Environment Definition, NASA CR-195315, Feb. 1994.

${ }^{4}$ Henderson, Sammy W., Paul J.M. Suni, Charley P. Hale, Stephen M. Hannon, James R. Magee, Dale L. Bruns, and Eric H. Yuen, "Coherent Laser Radar at
2 microns Using Solid State Lasers," IEEE Transactions on Geoscience and Remote Sensing, vol. 31, no. 1, Jan. 1993, pp. 4-15.

${ }^{5}$ Pueschel, R.F., J.M. Livingston, G.V. Ferry, and T.E. DeFelice, "Aerosol Abundances and Optical Characteristics in the Pacific Basin Free Troposphere," Atmospheric Environment, Mar. 1994, vol. 28, no. 5, pp. 951-960.

${ }^{6}$ Rothermel, Jeffry, David A. Bowdle, J. Michael Vaughan, and Madison J. Post, "Evidence of a Tropospheric Aerosol Backscatter Background Mode," Applied Optics, vol. 28, no. 6, Mar. 15, 1989, pp. 1040-1104. 

Public reponing burden for this collection of intormation is estimated to average 1 hour per response, including the time for reviewing instructions, searching existing data sources. gathering and maintaining the data needed. and completing and reviewing the collection of intormation. Send comments regarding this burden estimate or any other aspect of this collection of intormation. including sugoestions for reducing this burden, to Weshington Headquarters Services, Directorate for Intormation Operations and Reports, 1215 Jefterson Davis Highway. Sune 1204 , Arlington, VA 22202-4302, and to the Otfice of Manegement and Budgel. Paperwork Reduction Project (0704-0188), Washington, DC 20503.

\begin{tabular}{|l|l|l|}
\hline 1. AGENCY USE ONLY (Leave blank) & $\begin{array}{c}\text { 2. REPOAT DATE } \\
\text { July } 1997\end{array}$ & $\begin{array}{c}\text { 3. REPORT TYPE AND DATES COVERED } \\
\text { Technical Memorandum }\end{array}$ \\
\hline
\end{tabular}

\section{TITLE AND SUBTIILE}

The Use of a Lidar Forward-Looking Turbulence Sensor for Mixed-Compression

Inlet Unstart Avoidance and Gross Weight Reduction on a High Speed Civil

Transport

6. AUTHOR(S)

WU 529-50-24-00-RR-00-000

David Soreide, Rodney K. Bogue, Jonathan Seidel, and L.J. Ehernberger

NASA Dryden Flight Research Center

P.O. Box 273

Edwards, Califomia 93523-0273

8. PERFORMING ORGANIZATION

REPOAT NUMEER

H-2186

9. SPONSORING/MONTTORING AGENCY NAME(S) AND ADDRESS(ES)

10. SPONSORINGMONITORING AGENCY REPORT NUMBER

National Aeronautics and Space Administration

Washington, DC 20546-0001

NASA TM-104332

11. SUPPLEMENTAFY NOTES

Presented at the 33rd AIAA/ASME/SAE/ASEE Joint Propulsion Conference and Exhibit, July 6-9, 1997, Seattle, Washington

12. DISTRIBUTIONAVAILABILTYY STATEMENT

12b. DISTAIBUTION CODE

Unclassified-Unlimited

Subject Category 07

13. ABSTRACT (Maximum 200 words)

Inlet unstart causes a disturbance akin to severe turbulence for a supersonic commercial airplane. Consequently, the current goal for the frequency of unstarts is a few times per fleet lifetime. For a mixed-compression inlet, there is a tradeoff between propulsion system efficiency and unstart margin. As the unstart margin decreases, propulsion system efficiency increases, but so does the unstart rate. This paper intends to first, quantify that tradeoff for the High Speed Civil Transport (HSCT) and second, to examine the benefits of using a sensor to detect turbulence ahead of the airplane. When the presence of turbulence is known with sufficient lead time to allow the propulsion system to adjust the unstart margin, then inlet unstarts can be minimized while overall efficiency is maximized. The NASA Airborne Coherent Lidar for Advanced InFlight Measurements program is developing a lidar system to serve as a prototype of the forward-looking sensor. This paper reports on the progress of this development program and its application to the prevention of inlet unstart in a mixedcompression supersonic inlet. Quantified benefits include significantly reduced takeoff gross weight (TOGW), which could increase payload, reduce direct operating costs, or increase range for the HSCT

\section{SUBJECTTERMS}

SR-71 aircraft, DC-8 aircraft, Inlet aircraft, Alarm systems, Aircraft instrumentation, Lidar, High Speed Civil Transport, Laser optical radar

\begin{tabular}{|l|l|l|}
\hline $\begin{array}{l}\text { 17. SECURTY CLASSIFICATION } \\
\text { OF REPORT } \\
\text { Unclassified }\end{array}$ & $\begin{array}{l}\text { 18. SECURTY CLASSIFICATION } \\
\text { OF THIS PACE } \\
\text { Unclassified }\end{array}$ & $\begin{array}{l}\text { 19. SECURTY CLASSIFICATION } \\
\text { OF ABSTRACT } \\
\text { Unclassified }\end{array}$ \\
\hline
\end{tabular}

15. NUMBER OF PAGES

17

16. PAICE CODE

$\mathrm{A03}$

20. UMTATION OF ABSTRACT

Unlimited 